\title{
Do gabapentin or pregabalin directly modulate the $\mu$ receptor?
}

\author{
Preeti Manandhar ${ }^{\text {Equal first author, } 1}$, Bridin Patricia Murnion ${ }^{\text {Equal first author, 2, } 3 \text {, Natasha L Grimsey }}{ }^{4}$, Mark Connor ${ }^{1}$, Marina \\ Santiago ${ }^{\text {Corresp. } 1}$ \\ 1 Department of Biomedical Sciences, Macquarie University, Sydney, New South Wales, Australia \\ 2 Drug and Alcohol Services, Central Coast Local Health District, Hamlyn Terrace, Australia \\ 3 School of Medicine and Public Health, University of Newcastle, Newcastle, Australia \\ 4 Department of Pharmacology and Clinical Pharmacology, University of Auckland, Auckland, New Zealand \\ Corresponding Author: Marina Santiago \\ Email address: marina.junqueirasantiago@mq.edu.au
}

Background. Pregabalin and gabapentin improve neuropathic pain symptoms but there are emerging concerns regarding their misuse. This is more pronounced among patients with substance use disorder, particularly involving opioids. Co-ingestion of gabapentinoids with opioids is increasingly identified in opioid related deaths, however, the molecular mechanism behind this is still unclear. We have sought to determine whether pregabalin or gabapentin directly modulates acute $\mu$ receptor signaling, or $\mu$ receptor activation by morphine.

Methods. The effects of pregabalin and gabapentin were assessed in HEK 293 cells stably transfected with the human $\mu$ receptor. Their effect on morphine induced hyperpolarization, cAMP production and ERK phosphorylation were studied using fluorescent-based membrane potential assay, bioluminescence based CAMYEL assay and ELISA assay, respectively. Pregabalin/gabapentin effects on morphine-induced hyperpolarization were also investigated in AtT20 cells.

Results. Pregabalin or gabapentin ( $1 \mu \mathrm{M}, 100 \mu \mathrm{M}$ each) did not activate the $\mu$ receptor or affect $\mathrm{K}$ channel activation or ERK phosphorylation produced by morphine. Neither drug affected the desensitization of $\mathrm{K}$ channel activation produced by prolonged (30 min) application of morphine. Gabapentin $(1 \mu \mathrm{M}, 100 \mu \mathrm{M})$ and pregabalin $(1 \mu \mathrm{M})$ did not affect inhibition of forskolin-stimulated cAMP production by morphine. However, pregabalin $(100 \mu \mathrm{M})$ potentiated forskolin mediated cAMP production, although morphine still inhibited cAMP levels with a similar potency to control.

Discussion. Pregabalin or gabapentin did not activate or modulate $\mu$ receptor signaling in three different assays. Our data do not support the hypothesis that gabapentin or pregabalin augment opioid effects through direct or allosteric modulation of the $\mu$ receptor. Pregabalin at a high concentration increases cAMP production independent of morphine. The mechanism of enhanced opioid-related harms from coingestion of pregabalin or gabapentin with opioids needs further investigation. 


\section{Do gabapentin or pregabalin directly modulate the $\mu$} 2 receptor?

3

4

5 Preeti Manandhar ${ }^{1,}$, , Bridin Patricia Murnion ${ }^{2,}$, , Natasha L Grimsey ${ }^{3}$, Mark Connor ${ }^{1}$, Marina 6 Santiago $^{1}$

7

$8 \quad{ }^{1}$ Dept Biomedical Sciences, Macquarie University, Sydney, New South Wales, Australia

$9{ }^{2}$ Drug and Alcohol Services, Central Coast Local Health District, Hamlyn Terrace, Australia.

$10{ }^{2}$ School of Medicine and Public Health, University of Newcastle, Newcastle, Australia.

$11{ }^{3}$ Dept of Pharmacology and Clinical Pharmacology, University of Auckland, Auckland, New 12 Zealand.

13

14 Corresponding Author:

15 Marina Santiago $^{1}$

16 Level 1, 75 Talavera Rd, North Ryde, NSW2113, Australia

17 Email address: marina.junqueirasantiago@mq.edu.au

18

19

20

21

22

23

24

25

26

27

28

29

30

31

32

33

34

35

36

37

* These authors contributed equally to this work.

(1)




\section{Abstract}

41

Background. Pregabalin and gabapentin improve neuropathic pain symptoms but there are emerging concerns regarding their misuse. This is more pronounced among patients with

Methods. The effects of pregabalin and gabapentin were assessed in HEK 293 cells stably transfected with the human $\mu$ receptor. Their effect on morphine induced hyperpolarization, cAMP production and ERK phosphorylation were studied using fluorescent-based membrane potential assay, bioluminescence based CAMYEL assay and ELISA assay, respectively. Pregabalin/gabapentin effects on morphine-induced hyperpolarization were also investigated in AtT20 cells.

55

Results. Pregabalin or gabapentin $(1 \mu \mathrm{M}, 100 \mu \mathrm{M}$ each) did not activate the $\mu$ receptor or affect $\mathrm{K}$ channel activation or ERK phosphorylation produced by morphine. Neither drug affected the desensitization of $\mathrm{K}$ channel activation produced by prolonged (30 min) application of morphine. Gabapentin $(1 \mu \mathrm{M}, 100 \mu \mathrm{M})$ and pregabalin $(1 \mu \mathrm{M})$ did not affect inhibition of forskolinstimulated cAMP production by morphine. However, pregabalin $(100 \mu \mathrm{M})$ potentiated forskolin mediated cAMP production, although morphine still inhibited cAMP levels with a similar potency to control.

Discussion. Pregabalin or gabapentin did not activate or modulate $\mu$ receptor signaling in three different assays. Our data do not support the hypothesis that gabapentin or pregabalin augment opioid effects through direct or allosteric modulation of the $\mu$ receptor. Pregabalin at a high concentration increases cAMP production independent of morphine. The mechanism of enhanced opioid-related harms from co-ingestion of pregabalin or gabapentin with opioids needs further investigation.

\section{Introduction}

Gabapentin and pregabalin improve analgesia in acute perioperative pain and chronic neuropathic pain (Finnerup et al., 2015; Schug et al., 2015). They are commonly used as an opioid-sparing agent (Freedman \& O'Hara, 2008; Tiippana et al., 2007), particularly in opioidtolerant patients (Simpson \& Jackson, 2017). Despite clinical benefit, there are increasing reports

77 of abuse of these medications (Cairns et al., 2019). Gabapentin and pregabalin have been 
78 reported to enhance the psychoactive effect of opioids by people who use the drugs in an 79 unregulated fashion (Baird et al., 2014; Lyndon et al., 2017). Coronial post-mortem data 80 identifies the appearance of pregabalin or gabapentin in an increasing proportion of opioid81 related fatalities (Cairns et al., 2019; Lyndon et al., 2017).

82

83

84

85

86

87

88

89

90

91

92

93

94

95

96

97

98

99

100

101

102

103

104

105

106

107

108

109

110

111

112

113

114

115

116

117

While both gabapentin and pregabalin are GABA analogues, no direct action at GABA receptors has been identified (Lanneau et al., 2001; Jensen et al., 2002; Stahl et al., 2013). The analgesic effect is thought to be a result of these drug's interaction with the alpha-2-delta subunit of the presynaptic voltage-gated calcium channel (Chincholkar, 2018). However, multiple potential mechanisms of action have been reported, including interaction with L-amino transport system, action at N-methy-D-aspartate (NMDA) receptors, blockade of voltage-gated sodium channels and increased conductance of potassium channels (Chincholkar, 2018; Manville \& Abbott, 2018; Taylor et al., 2018)

The $\mu$ receptor (previously known as $\mu$ opioid receptor) and its endogenous ligands are crucial regulators of cells and circuits that detect, integrate, and respond to painful sensations. Clinically used opioids exert their analgesic action through activation of the $\mu$ receptor (Al-Hasani \& Bruchas, 2011), however, a few such as tapentadol and tramadol may also modulate other painrelated targets (Faria et al., 2018). More recently, the analgesic potential of allosteric modulators of the $\mu$ receptor have been investigated (Burford et al., 2015). During an acute pain episode, a positive allosteric modulator could enhance endorphin effect at the $\mu$ receptor on pain modulating sites; however, it is expected to have minimal off-target effect as in other areas endogenous ligands may not be present to activate the $\mu$ receptor.

Animal studies suggest gabapentinoid activity in modulating neuropathic pain is opioid independent (Kremer et al., 2016). However, different mechanisms may underpin opioid-sparing, reward, and respiratory depression/sedation, with the latter properties leading to misuse and toxicity. Pregabalin has been shown to reverse the tolerance to morphine-induced respiratory depression in mice (Lyndon et al., 2017) and potentiation of morphine signaling through allosteric modulation of the $\mu$ receptor could account for this effect.

To date, there has been no investigation of the actions of gabapentin or pregabalin at the $\mu$ receptor. We, therefore, hypothesized that gabapentin and pregabalin enhance opioid effect through direct modulation of the $\mu$ receptor. The current study investigated recombinant human $\mu$ receptor modulation of three distinct effector systems: activation of $\mathrm{G}$ protein-coupled inwardly rectifying potassium channels (GIRK), inhibition of adenylyl cyclase, and stimulation of extracellular signal-regulated kinase (ERK) phosphorylation.

\section{Materials \& Methods}

Peer) reviewing PDF | (2020:09:52945:1:0:NEW 25 Jan 2021) 


\section{Cell Culture}

119

The study was performed in Human Embryonic Kidney Flp-In ${ }^{\text {TM}}-293$ (HEK) cells from Life

121 Technologies (R75007 - Thermo Fisher Scientific, derived from ATCC CRL-1573) and mouse pituitary (AtT20) cells from ATCC (CRL-1795). HEK cells were stably transfected with human GIRK 4 construct subcloned into pcDNA3.1+ (Gillis et al., 2020) and 3-haemagglutinin tagged human $\mu$ receptor construct subcloned into pcDNA5/FRT/TO (HEK- $\mu)$. AtT20 Flp-In ${ }^{\mathrm{TM}}$ cells were stably transfected with the same human $\mu$ receptor-pcDNA5/FRT/TO (AtT20- $\mu$ ) as described previously (Knapman et al., 2013) using Fugene HD. The integration of GIRK-4pcDNA3. $1^{+}$plasmids led to geneticin resistant cells and a single cell was expanded to produce a clonal cell line. Human $\mu$ receptor-pcDNA5/FRT/TO was cotransfected with pOG44 into the Flp-In ${ }^{\text {TM }}$ site according to manufacturer's instructions (Thermo Fisher Scientific). Selection was performed using $150 \mu \mathrm{g} / \mathrm{mL}$ hygromycin gold and resistant cells are considered isogenic due to integration of the plasmid into the same genomic locus in every clone (Flp- $\operatorname{In}^{\mathrm{TM}}$ system). Cells were cultured and maintained in growth media composed of Dulbecco's modified Eagle's medium (DMEM) supplemented with 10\% fetal bovine saline (FBS), $100 \mathrm{U} / \mathrm{mL}$ penicillin, 100 $\mu \mathrm{g} / \mathrm{mL}$ streptomycin, and $80 \mu \mathrm{g} / \mathrm{mL}$ hygromycin gold. HEK cells additionally had 400 $\mu \mathrm{g} / \mathrm{mL}$ geneticin added to the culture media. All cells were stored in a humidified incubator at $37^{\circ} \mathrm{C}$ in an atmosphere with $5 \% \mathrm{CO}_{2}$.

137

\section{Hyperpolarization assay}

139

140

The effect of pregabalin or gabapentin on morphine induced hyperpolarization was evaluated using a fluorescence-based membrane potential assay (Knapman et al., 2013). One day before the assay, cells were detached from the flask with trypsin/EDTA and resuspended in Leibovitz (L-15) supplemented with $1 \% \mathrm{FBS}, 100 \mathrm{U} / \mathrm{mL}$ penicillin, $100 \mu \mathrm{g} / \mathrm{mL}$ streptomycin and $15 \mathrm{mM}$ bottomed plates to achieve a monolayer and incubated overnight at $37^{\circ} \mathrm{C}$ and ambient $\mathrm{CO}_{2}$. FLIPR membrane potential blue dye was reconstituted to $50 \%$ of the manufacturer's recommended concentration in modified Hank's buffered salt solution (HBSS). This was composed of (in $\mathrm{mM}$ ) NaCl 145, $\mathrm{Na}_{2} \mathrm{HPO} 4$ 0.338, $\mathrm{NaHCO}_{3}$ 4.17, HEPES 22, $\mathrm{KH}_{2} \mathrm{PO}_{4} 0.441$, $\mathrm{MgSO}_{4}$ 0.407, $\mathrm{MgCl}_{2}$ 0.493, $\mathrm{CaCl}_{2} 1.26$, glucose 5.56 (pH 7.4, osmolarity $315 \pm 15$ ). $90 \mu \mathrm{L}$ of dye was added to each well and incubated for 60 minutes at $37^{\circ} \mathrm{C}$ in ambient $\mathrm{CO}_{2}$ prior to fluorescence reading. All drugs were diluted in HBSS and loaded on the compound plate. Drug concentrations were ten times that of the final concentration to accommodate for dilution after addition to the well. Fluorescence was measured using FlexStation 3 plate reader (Molecular Devices) with an excitation wavelength of $530 \mathrm{~nm}$ and emission of $565 \mathrm{~nm}$ at 2 second intervals. 
156 Baseline fluorescence was recorded for 2 minutes after which $20 \mu 1$ of vehicle or drug was

157

158

159

160

161

162

163

164

165

166

167

168

169

170

171

172

173

174

175

176

177

178

179

180

181

182

183

184

185

186

187

188

189

190

191

192

193

194

195

added. Data were calculated as a percentage change from baseline fluorescence after correction for vehicle addition.

\section{Assay for cAMP measurement}

Bioluminescence based cAMP assay was performed in HEK- $\mu$ cells to investigate the effect of pregabalin or gabapentin on morphine mediated inhibition of cAMP production (Sachdev et al., 2019; Manandhar et al., 2020). The cells for the assay were detached from the flask with trypsin/EDTA and seeded in a $10 \mathrm{~cm}$ plate at a density of 6 million cells to reach 60 $70 \%$ confluency in 24 hours. Next day, pcDNA3L-His-CAMYEL plasmid was transiently transfected into the cells using-linear polyethyleneimine (PEI) at a ratio of 1:6 (DNA: PEI). The transfected cell plate was then incubated overnight at $37^{\circ} \mathrm{C}$ in a humidified atmosphere with $5 \%$ $\mathrm{CO}_{2} .24$ hours after transfection, the cells were detached from the plate and resuspended in L15 (no phenol red), supplemented with $1 \% \mathrm{FBS}, 100 \mathrm{U} / \mathrm{mL}$ penicillin, $100 \mu \mathrm{g} / \mathrm{mL}$ streptomycin and $15 \mathrm{mM}$ glucose. Cells were then plated in 96 well white-walled clear bottom plates precoated with poly-D-lysine and incubated overnight at $37^{\circ} \mathrm{C}$ in ambient $\mathrm{CO}_{2}$. On the day of the assay, all drugs were prepared at ten times the final concentration in HBSS containing $30 \mu \mathrm{M}$ forskolin to reach the desired final concentration upon adding to the cell suspension. Cellular cAMP levels were measured using kinetics settings in the FlexStation 3 and luminescence detection was set at an emission spectrum of $461 \mathrm{~nm}$ (Rluc) and $542 \mathrm{~nm}$ (YFP). 10 $\mu \mathrm{L}$ coelenterazine-h substrate was added, and the baseline luminescence was measured for 5 minutes before adding the drugs. Inverse BRET ratio was calculated at the emission of 461/542 so that the increase in ratio corresponds to increase cAMP production. The area under the curve was calculated for each concentration of the drug after correcting for vehicle and data were expressed as a percentage change in forskolin response after drug addition.

\section{Whole cell ELISA for measuring ERK phosphorylation}

Opioid-induced ERK phosphorylation was measured using whole cell ELISA in HEK- $\mu$ cells. The cells were resuspended in L-15 and plated in a 96 well clear microplate pre-coated with poly-D-lysine and incubated overnight at $37^{\circ} \mathrm{C}$. The next day, cells were serum starved for an hour in serum free L-15 before adding the drugs. Cells were then treated for 5 minutes with different concentrations of drugs prepared in serum free L-15. Some wells were separated for treatment with the positive control (100 nM PMA, Phorbol 12-Myristate 13-Acetate) and negative control (10 $\mu \mathrm{M}$ U0126). After 5 minutes of incubation, drug solution was removed, and the plate was immediately placed on ice. Cells were fixed using 4\% paraformaldehyde for 15 minutes at room temperature. The cells were washed 3 times with PBS then permeabilized with $0.1 \%$ Triton- $X$ in PBS. After 30 minutes, the permeabilizing agent was removed and the plate was incubated at room temperature for 2 hours with blocking solution (5\% bovine fetal albumin 
196 in PBS with $0.01 \%$ Tween-20). After 2 hours of blocking, the solution was removed, and cells

197

198

199

200

201

202

203

204

205

206

207

208

209

210

211

212

213

214

215

216

217

218

219

220

221

222

223

224

225

226

227

228

229

230

231

232

233

234

235

were incubated overnight at $4{ }^{\circ} \mathrm{C}$ with rabbit $\alpha$-phospho-p44/42 MAPK (Thr202/Tyr204) antibody diluted at a ratio of 1:500 with 1\% BSA in PBS supplemented with $0.1 \%$ Tween-20 (PBS-T). Next day the cells were washed 3 times with washing buffer (PBS-T) and treated with secondary antibody (1:5000 $\alpha$ - rabbit IgG HRP-linked antibody in PBS-T containing 1\% BSA) for 2 hours. Cells were washed 3 times and incubated in the dark with ELISA peroxidase substrate $(3,3$ ',5,5'-tetramethylbenzidine) for 45 mins. Finally, the reaction was stopped using $1 \mathrm{~N} \mathrm{HCl}$. Absorbance was measured at $450 \mathrm{~nm}$ using the BMG PheraStar FS plate reader. Data were expressed as mean \pm SEM for five individual experiments performed in triplicates and the concentration-response curve was plotted after normalizing to the positive control.

\section{Data Analysis}

All data were expressed as mean \pm SEM of at least five independent experiments performed in duplicates unless otherwise stated. Concentration-response curves were plotted using the fourparameter non-linear regression equation in GraphPad PRISM 8 (GraphPad Software, San

Diego, CA). Data were statistically tested using one way ANOVA corrected using Bonferroni method within each set of comparisons. Two tailed unpaired student t-test was used to compare the mean of $\mathrm{EC}_{50}$ and Emax for CAMYEL assay in measuring the effect of $100 \mu \mathrm{M}$ pregabalin and isoproterenol in forskolin response. $\mathrm{P}$ values $<0.05$ were considered significant for all the analysis.

\section{Materials}

Morphine was a kind gift from the University of Sydney, Australia. Pregabalin and gabapentin were purchased from Tocris, Australia. Forskolin was provided by Ascent Scientific Ltd. Culture reagents and buffer salts were supplied by Sigma Aldrich (Castle Hill, Australia) or Thermo Fisher Scientific (Massachusetts, USA). The CAMYEL plasmid encoding the cAMP sensor YFP-EPac-RLuc was a generous gift from Dr Angela Finch, University of New South Wales, Australia. Phospho-ERK1/2 antibody and anti-rabbit IgG HRP linked antibody were from Cell Signaling Technologies (Massachusetts, USA). Antibiotics were from Invivogen (San Diego, USA) and coelenterazine h was from Promega (Alexandria, Australia). The membrane potential dye was purchased from Molecular Devices, CA.

\section{Results}

The effects of pregabalin and gabapentin on morphine-induced $\mathrm{K}$ channel activation was investigated in HEK cells co-expressing GIRK4 and human $\mu$ receptor. Morphine caused maximum hyperpolarization at $13 \pm 4 \%$ with $p$ EC50 of $6.6 \pm 0.5$. Incubation of pregabalin or

Peer] reviewing PDF | (2020:09:52945:1:0:NEW 25 Jan 2021) 
236 gabapentin at $1 \mu \mathrm{M}$ or $100 \mu \mathrm{M}$ for 5 minutes did not change the morphine-induced GIRK

237

238

239

240

241

242

243

244

245

246

247

248

249

250

251

252

253

254

255

256

257

258

259

260

261

262

263

264

265

266

267

268

269

270

271

272

273

274

275

activation in HEK- $\mu$ cells (Figure 1a, $\mathrm{c}$ and e). Emax, $p$ EC50 and $\mathrm{p}$ values are shown in Table 1.

To ensure the effect was not cell-specific, the hyperpolarization response to morphine with and without pregabalin or gabapentin was assessed in AtT20- $\mu$ cells. While the maximum hyperpolarization caused by morphine was higher in AtT20- $\mu$ cells as compared to HEK- $\mu$ cells, incubation with pregabalin or gabapentin did not affect the response to morphine (Figure 1b, $d$ and f). The corresponding Emax, $p \mathrm{EC} 50$ and $\mathrm{p}$ values are shown in Table 1.

Modulation of agonist dependent acute desensitization was investigated by incubating cells for 5 minutes with $100 \mu \mathrm{M}$ pregabalin or gabapentin, followed by the addition of $10 \mu \mathrm{M}$ morphine and fluorescence monitoring for 30 minutes (Figure 2). Acute desensitization was measured as change in area under the curve after addition of pregabalin/gabapentin or vehicle. Pregabalin or gabapentin did not change acute desensitization of $\mu$ receptor in both AtT $20-\mu(p=>0.99$ for pregabalin and $p=0.88$ for gabapentin) or HEK- $\mu$ cells $(p=>0.99$ for pregabalin and gabapentin). In HEK- $\mu$ cells, membrane hyperpolarization in response to morphine, although lower in amplitude, persisted with minimal abatement over the 30 minutes it was measured (Figure 2a). In comparison, morphine response was greater in magnitude in AtT20- $\mu$ cells but showed attenuation over 30 minutes (Figure 2b).

To investigate the effect of prolonged pre-treatment with gabapentin/pregabalin on the opioid response in HEK- $\mu$ cells, the morphine concentration-response curve was performed after 60 minutes incubation with $100 \mu \mathrm{M}$ pregabalin or gabapentin. There was no difference in the morphine response in all 3 groups, with maximum decrease in fluorescence at $16 \pm 2 \%$ in control and $15 \pm 2 \%(\mathrm{p}=0.84)$ and $16 \pm 3 \%(\mathrm{p}=>0.99)$ in the presence of $100 \mu \mathrm{M}$ pregabalin and gabapentin respectively, with a constant potency value of $6.7 \pm 0.3$ in all three conditions (Figure $3)$.

The effect of pregabalin/gabapentin on morphine response was further evaluated in a bioluminescence-based forskolin-stimulated cAMP assay in HEK cells. $1 \mu \mathrm{M}$ pregabalin, 1 and $100 \mu \mathrm{M}$ gabapentin co-administered with forskolin did not modulate the changes in cAMP levels mediated by forskolin alone or forskolin with morphine. Morphine inhibited the forskolinstimulated increase in cAMP by $41 \pm 4 \%$ with $p \mathrm{EC} 50$ of $6.8 \pm 0.2$. In the presence of $1 \mu \mathrm{M}$ pregabalin, $1 \mu \mathrm{M}$ or $100 \mu \mathrm{M}$ gabapentin, maximum inhibition of cAMP by morphine was $37 \pm 3 \%(\mathrm{p}=>0.99), 47 \pm 5 \%(\mathrm{p}=>0.99)$ and $35 \pm 4 \%(\mathrm{p}=0.95)$ respectively with corresponding $p \mathrm{EC} 50$ values as $6.9 \pm 0.1,6.8 \pm 0.2$ and $7.0 \pm 0.2$ (Figure 4). However, $100 \mu \mathrm{M}$ pregabalin co-applied with forskolin augmented the cAMP levels compared to forskolin alone (Figure $4 \mathrm{~d}$ ). The assay was repeated with concentrations of pregabalin between $10 \mu \mathrm{M}$ and 10 $\mathrm{nM}$. This identified pregabalin concentrations $\geq 100 \mu \mathrm{M}$ cause an increase in cAMP when coapplied with forskolin.

PeerJ reviewing PDF | (2020:09:52945:1:0:NEW 25 Jan 2021) 
276

277

278

279

280

281

282

283

284

285

286

287

288

289

290

291

292

293

294

295

296

297

298

299

300

301

302

303

304

305

306

307

308

309

310

311

312

313

314

315

To test the hypothesis that this increase may be due to activation of $\mathrm{G} \alpha_{\mathrm{s}}$, the concentrationresponse curve of forskolin and isoproterenol (a Gs agonist) in the presence of $100 \mu \mathrm{M}$ pregabalin in HEK GIRK4 wild type cells were plotted. Pregabalin did not affect the maximum response of forskolin but caused a significant increase in potency of forskolin (Figure $4 \mathrm{e}, \mathrm{p}=$ 0.015), however, it did not affect the response of isoproterenol (Figure 4f).

Finally, the effect of gabapentin or pregabalin on the ligand interaction of $\mu$ receptor on ERK phosphorylation pathway was investigated using ELISA. Acute application of $100 \mu \mathrm{M}$ pregabalin $(\mathrm{p}>0.99)$ and $100 \mu \mathrm{M}$ gabapentin $(\mathrm{p}>0.99)$ did not affect the phosphorylation of ERK on HEK $\mu$ cells. We found that morphine $E_{\max }$ for ERK1/2 phosphorylation was $28 \pm 2 \%$ of the PMA response with $p \mathrm{EC} 50$ value of $6.9 \pm 0.2$. There was no significant change in the morphineinduced phosphorylation in the presence of $1 \mu \mathrm{M}$ or $100 \mu \mathrm{M}$ of either pregabalin or gabapentin (Figure 5). Morphine caused maximum phosphorylation of $21 \pm 4 \% \quad(p=>0.99)$ and $22 \pm 4 \%$ (p $=>0.99)$ with $1 \mu \mathrm{M}$ or $100 \mu \mathrm{M}$ pregabalin with $p \mathrm{EC} 50$ of $6.6 \pm 0.4(\mathrm{p}=0.31)$ and $6.5 \pm 0.4(\mathrm{p}=$ $0.23)$, respectively. Co-administration of $1 \mu \mathrm{M}$ or $100 \mu \mathrm{M}$ gabapentin with morphine resulted in maximum phosphorylation of $30 \pm 4 \%(p=0.73)$ and $27 \pm 4 \%(p=0.92)$ respectively with a $p$ EC50 value of $6.7 \pm 0.3(\mathrm{p}=>0.99)$

\section{Discussion}

In this study, we have shown that neither pregabalin nor gabapentin affects morphine signaling at the $\mu$ receptor when modulation of GIRK activation, ERK phosphorylation or cAMP production was measured using in vitro assays. No direct effect of pregabalin or gabapentin on GIRK activation or ERK phosphorylation was observed. Neither gabapentin nor lower concentrations of pregabalin impacted forskolin-stimulated cAMP, nor did it alter the inhibition of forskolin-stimulated cAMP produced by morphine. Interestingly, 100 $\mu \mathrm{M}$ pregabalin enhanced forskolin-stimulated cAMP, which has not previously been demonstrated. Finally, the presence of pregabalin and gabapentin did not affect acute desensitization of GIRK activation in response to prolonged exposure to morphine. These data suggest that direct interaction of pregabalin and gabapentin with the $\mu$ receptor is unlikely to explain its use as an adjuvant to opioids in situations of unregulated use, and any positive effects of pregabalin and gabapentin on opioid user experience may be mediated through interactions with the cells and circuits that are modulated by $\mu$ receptors.

Pregabalin concentration at its site of action is not known, however, a single $300 \mathrm{mg}$ dose of pregabalin in peri-operative patients can result in cerebrospinal fluid (CSF) concentrations of approximately $0.4 \mu \mathrm{g} / \mathrm{mL}(2.5 \mu \mathrm{M})$ (Buvanendran et al., 2010). $100 \mu \mathrm{M}$ pregabalin is also higher than measured in plasma after single dosing $(12.5-50 \mu \mathrm{M})$ or steady-state after multiple dosing (80 - $90 \mu \mathrm{M})$ (Bockbrader et al., 2010; May et al., 2007). However, the above concentrations 
316 were measured in patients taking pregabalin at the recommended clinical dosage, which is not 317 necessarily relevant when these drugs are misused. It is evident that those with substance use 318 disorder ingest large doses of pregabalin (WHO, 2018). In a two-year study of post-mortem 319 blood pregabalin concentration, it was observed that one-third of the seventy analyzed samples

320

321

322

323

324

325

326

327

328

329

330

331

332

333

334

335

336

337

338

339

340

341

342

343

344

345

346

347

348

349

350

351

352

353

354

355 were above $17 \mathrm{mg} / \mathrm{L}(106 \mu \mathrm{M})$ (Eastwood \& Davison, 2016). In a study of drug-affected drivers, pregabalin plasma concentration ranged from 0.68 to $111.6 \mathrm{mg} / \mathrm{L}(3.8-700 \mu \mathrm{M})$ (Kriikku et al., 2014). Concentration of gabapentin detected in CSF after a single dose of 600-1200 $\mathrm{mg}$ ranges between $0.15 \mu \mathrm{g} / \mathrm{mL}$ and $0.44 \mu \mathrm{g} / \mathrm{mL}$, equating to $0.9-2.6 \mu \mathrm{M}$ (Ben-Menachem et al., 1992). The $1 \mu \mathrm{M}$ concentrations of both pregabalin and gabapentin used in our assays are therefore broadly similar to those expected in CSF in routine clinical practice. Likewise, the higher concentrations are consistent with reports associated with drug intoxication, at least for pregabalin. Activation of a novel signaling pathway at higher concentrations could contribute to toxicity seen at these higher doses.

The finding that higher dose pregabalin augmented forskolin-stimulated cAMP activity with no effect from gabapentin also identifies a previously unrecognized difference in the drugs. Pregabalin and gabapentin are often considered interchangeable clinically. There are some differences in pharmacokinetic parameters, such as dose-dependent (non-linear) absorption and lower bioavailability of gabapentin (Bockbrader et al., 2010). Looking at human efficacy data, pregabalin shows a dose-dependent improvement in neuropathic pain, while gabapentin shows no dose-response relationship (Finnerup et al., 2015). The number needed to harm in clinical trials is lower for pregabalin than gabapentin (Finnerup et al., 2015), and heroin users indicate a preference for pregabalin (Lyndon et al., 2017). We have demonstrated that higher concentration of pregabalin increased cAMP levels which was not seen with gabapentin. The increment in cAMP possibly being independent of $\mathrm{G} \alpha_{\mathrm{s}}$ and $\mu$ receptor being activated by Gi/Go, highlight the need of more studies to better understand this unknown mechanism and if it has any link to the synergistic toxicity seen with opioid and pregabalin.

As the lethality of pregabalin/gabapentin combined with opioids is increasingly recognized, so has the need to understand the molecular biology of this toxicity. Lyndon et al (2017) identified that pregabalin alone causes respiratory depression that is not blocked by naloxone, and therefore not an opioid-mediated effect. Pregabalin binding to an allosteric site on the $\mu$ receptor is still a possibility but our data concur with Lyndon et al (2017) in that no direct effect on the $\mu$ receptor signaling was seen with pregabalin and gabapentin. In the same study, Lyndon noted opioid-tolerant mice lose their tolerance to opioid-induced respiratory depression when pregabalin is administered along with morphine. Acute desensitization is arguably an early step for the development of tolerance (Borgland et al., 2001). Our study demonstrated no changes in acute desensitization to morphine with or without pregabalin or gabapentin, suggesting that any changes in tolerance associated with pregabalin is not linked to a change in morphine-mediated acute desensitization of the $\mu$ receptor. However, many kinases 
356 have been shown to be involved in $\mu$ receptor acute desensitization which leaves open the 357 possibility of pregabalin and gabapentin affecting desensitization by mechanism(s) activated by 358 other opioids or by pathways not present in the cell lines tested in this study. Considering the 359 results presented in this study, the effect of pregabalin in tolerance is more likely to be an 360 indirect effect through common pathways.

361

362 Both positive and negative allosteric modulators of the $\mu$ receptor have been identified (Burford 363 et al., 2015). Recent data suggest that allosteric ligands may have effects at multiple opioid

364

365

366

367

368

369

370

371

372

373

374

375

376

377

378

379

380

381

382

383

384

385

386

387

388

389

390

391

392

393

394

\section{7}

389 receptor types, and an allosteric binding site that is conserved across opioid receptors may account for this finding (Livingston et al., 2018). This study did not demonstrate any augmentation or diminution of morphine signaling with either pregabalin or gabapentin. It is therefore unlikely that these compounds act as allosteric modulators of the $\mu$ receptor. Our experiments were conducted with only one orthosteric ligand, so agonist (probe) dependence has not been excluded. However, the fact that morphine with pregabalin or gabapentin in vivo have synergistic effect argue against this (Turan et al., 2004; Keskinbora et al., 2007)

Performing the experiments in different cell lines strengthens the robustness of the findings, hence we used two different cell lines. Although HEK cells showed a lower maximum response and minimal acute signal desensitization in response to prolonged exposure to morphine as compared to AtT20 cell, pregabalin or gabapentin did not alter morphine response in either HEK or AtT20 cells, which supports our findings.

\section{Conclusions}

In conclusion, this is the first study to look at the impact of pregabalin and gabapentin on functional assays of human $\mu$ receptor signaling. Gabapentin and pregabalin do not mediate their analgesic or toxic effects by a direct effect on the $\mu$ receptor. No allosteric modulation of $\mu$ receptor activity was identified in assays of GIRK, cAMP or ERK. High dose pregabalin caused increase in cAMP production, and the mechanism behind this warrants further investigation.

\section{References}


395

396

397

398

399

400

401

402

403

404

405

406

407

408

409

410

411

412

413

414

415

416

417

418

419

420

421

422

423

424

425

426

427

428

429

430

431

432

433

434

435

436

437

438

439

440

441

442

443

444

Al-Hasani R, \& Bruchas MR. (2011). Molecular mechanisms of opioid receptor-dependent signaling and behavior. Anesthesiology: The Journal of the American Society of Anesthesiologists, 115(6), 1363-1381. Baird CR, Fox P, \& Colvin LA. (2014). Gabapentinoid abuse in order to potentiate the effect of methadone: a survey among substance misusers. European Addiction Research, 20(3), 115-118. Ben-Menachem E, Persson LI, \& Hedner T. (1992). Selected CSF Biochemistry and Gabapentin concentrations in the CSF and plasma in patients with partial seizures after a single oral dose of gabapentin. Epilepsy Research, 11.1, 45-49

Bockbrader HN, Wesche D, Miller R, Chapel S, Janiczek N, \& Burger P. (2010). A comparison of the pharmacokinetics and pharmacodynamics of pregabalin and gabapentin. Clinical Pharmacokinetics, 49(10), 661-669.

Bockbrader HN, Radulovic LL, Posvar EL, Strand JC, Alvey CW, Busch JA, Randinitis EJ, Corrigan BW, Haig GM \& Boyd RA. (2010). Clinical Pharmacokinetics of pregabalin in healthy volunteers. The Journal of Clinical Pharmacology, 50(8), 941-950.

Borgland SL. (2001). Acute opioid receptor desensitization and tolerance: is there a link? Clinical and Experimental Pharmacology and Physiology , 28(3), 147-154.

Burford N, Traynor J, \& Alt A. (2015). Positive allosteric modulators of the $\mu$-opioid receptor: a novel approach for future pain medications. British Journal of Pharmacology, 172(2), 277-286.

Buvanendran A, Kroin JS, Kari M, \& Tuman KJ. (2010). Can a single dose of $300 \mathrm{mg}$ of pregabalin reach acute antihyperalgesic levels in the central nervous system? Regional Anesthesia \& Pain Medicine, 35(6), 535-538-535-538.

Cairns R, Schaffer AL, Ryan N, Pearson SA, \& Buckley NA. (2019). Rising pregabalin use and misuse in Australia: trends in utilization and intentional poisonings. Addiction, 114(6), 1026-1034.

Chincholkar M. (2018). Analgesic mechanisms of gabapentinoids and effects in experimental pain models: a narrative review. British Journal of Anaesthesia, 120(6), 1315-1334.

Eastwood JA, \& Davison E. (2016). Pregabalin concentrations in post-mortem blood - a two year study. Forensic Science International, 266, 197-201.

Faria J, Barbosa J, Moreira R, Queirós O, Carvalho F \& Dinis-Oliveira RJ. (2018). Comparative pharmacology and toxicology of tramadol and tapentadol. European Journal of Pain, 22(5), 827-844. Finnerup NB, Attal N, Haroutounian S, McNicol E, Baron R, Dworkin RH, Gilron I, Haanpää M, Hansson P \& Jensen TS. (2015). Pharmacotherapy for neuropathic pain in adults: a systematic review and meta-analysis. The Lancet Neurology, 14(2), 162-173.

Freedman BM, \& O'Hara E. (2008). Pregabalin has opioid-sparing effects following augmentation mammaplasty. Aesthetic Surgery Journal, 28(4), 421-424.

Gillis A, Gondin AB, Kliewer A, Sanchez J, Lim HD, Alamein C, Manandhar P, Santiago M, Fritzwanker S, Schmiedel F, Katte TA, Reekie T, Grimsey NL, Kassiou M, Kellam B, Krasel C, Halls ML, Connor M, Lane JR, Schulz S, Christie MJ \& Canals M. (2020). Low intrinsic efficacy for G protein activation can explain the improved side effect profiles of new opioid agonists. Science Signaling, 13(625).

Jensen AA, Mosbacher J, Elg S, Lingenhoehl K, Lohmann T, Johansen TN, Abrahamsen B, Mattson JP, Lehmann A \& Bettler Bernhard. (2002). The anticonvulsant gabapentin (Neurontin) does not act through $\gamma$-aminobutyric acid-B receptors. Molecular Pharmacology, 61(6), 1377-1384.

Keskinbora K, Pekel AF, Aydinli IJJop, \& management s. (2007). Gabapentin and an opioid combination versus opioid alone for the management of neuropathic cancer pain: a randomized open trial. Journal of Pain Symptom Management, 34(2), 183-189.

Knapman A, Santiago M, Du YP, Bennallack PR, Christie MJ, \& Connor M. (2013). A continuous, fluorescence-based assay of $\mu$-opioid receptor activation in AtT-20 cells. Journal of Biomolecular Screening, 18(3), 269-276.

Kremer M, Yalcin I, Nexon L, Wurtz X, Ceredig RA, Daniel D, Hawkes RA, Salvat E \& Barrot M. (2016). The antiallodynic action of pregabalin in neuropathic pain is independent from the opioid system. Molecular Pain, 12, 1744806916633477. 
445 Kriikku P, Wilhelm L, Rintatalo J, Hurme J, Kramer J, \& Ojanperä I. (2014). Pregabalin serum levels in apprehended drivers. Forensic Science International, 243, 112-116.

Lanneau C, Green A, Hirst WD, Wise A, Brown JT, Donnier E, Charles KJ, Wood M, Davies CH \& Pangalos MN. (2001). Gabapentin is not a GABAB receptor agonist. Neuropharmacology, 41(8), 965975.

Livingston KE, Stanczyk MA, Burford NT, Alt A, Canals M, \& Traynor JR. (2018). Pharmacologic evidence for a putative conserved allosteric site on opioid receptors. Molecular Pharmacology, 93(2), 157-167.

453 Lyndon A, Audrey S, Wells C, Burnell ES, Ingle S, Hill R, Hickman M, \& Henderson G. (2017). Risk to heroin users of polydrug use of pregabalin or gabapentin. Addiction, 112(9), 1580-1589. Manandhar P, Sachdev S \& Santiago M. (2020). Evaluating opioid-mediated adenylyl cyclase inhibition in live cells using a BRET-based assay. Spampinato S.M. (eds) Opioid Receptors. Methods in Molecular Biology. Vol 2110.

458 Manville RW \& Abbott GW. (2018). Gabapentin is a potent activator of KCNQ3 and KCNQ5 potassium 459 channels. Molecular Pharmacology, 94(4), 1155-1163.

460 May TW, Rambeck B, Neb R, \& Jürgens U. (2007). Serum concentrations of pregabalin in patients with 461 epilepsy: the influence of dose, age, and comedication. Therapeutic Drug Monitoring, 29(6), 789-794.

462 Sachdev S, Boyd R, Grimsey NL, Santiago M \& Connor M. (2019). Brodifacoum does not modulate 463 human cannabinoid receptor-mediated hyperpolarization of AtT20 cells or inhibition of adenylyl cyclase 464 in HEK 293 cells. PeerJ, 7, e7733.

465 Schug SA, Palmer GM, Scott DA, Halliwell R, \& Trinca J. (2015). Acute pain management: scientific 466 evidence. Acute Pain Management: Scientific Evidence, lxiv.

467 Simpson G, \& Jackson M. (2017). Perioperative management of opioid-tolerant patients. BJA Education, 468 17(4), 124-128.

469 Stahl SM, Porreca F, Taylor CP, Cheung R, Thorpe AJ, \& Clair A. (2013). The diverse therapeutic actions of pregabalin: is a single mechanism responsible for several pharmacological activities? Trends in Pharmacological Sciences, 34(6), 332-339.

Taylor Cp \& Harris EW. (2020). Analgesia with Gabapentin and Pregabalin may involve N-Methyl-dAspartate Receptors, Neurexins, and Thrombospondins. Journal of Pharmacology and Experimental Therapeutics, 374(1), 161-174.

Tiippana EM, Hamunen K, Kontinen VK, \& Kalso EJA. (2007). Do surgical patients benefit from perioperative gabapentin/pregabalin? A systematic review of efficacy and safety. Anesthesia \& Analgesia, 104(6), 1545-1556.

Turan A, Karamanlığlu B, Memiş D, Hamamcıoglu MK, Tükenmez B, Pamukçu Z, \& Kurt I. (2004). Analgesic effects of gabapentin after spinal surgery. Anesthesiology: The Journal of the American Society of Anesthesiologists, 100(4), 935-938.

WHO. (2018). Critical Review Report: Pregabalin. Retrieved from WHO Expert Committee Drug Dependence, forty-first meeting, 12-16 November 2018, Geneva 


\section{Table 1 (on next page)}

Activity of morphine with or without pregabalin or gabapentin in membrane potential assay in HEK and AtT20 cells expressing $\mu$ receptor. Summary of curve-derived parameters. 


\begin{tabular}{|l|l|l|l|l|l|l|l|l|}
\hline & \multicolumn{7}{|l|}{ HEK cells } & \multicolumn{2}{l|}{ AtT20 cells } \\
\hline & $\mathrm{E}_{\max }$ & $\mathrm{p}$ value & $p \mathrm{EC} 50$ & $\mathrm{p}$ value & $\mathrm{E}_{\max }$ & $\mathrm{p}$ value & $p$ EC50 & $\mathrm{p}$ value \\
\hline Control & $12.68 \pm 4 \%$ & & $6.6 \pm 0.5$ & & $29.76 \pm 1 \%$ & & $7.3 \pm 0.1$ & \\
\hline $100 \mu \mathrm{M}$ Pregabalin & $15.47 \pm 6 \%$ & 0.99 & $6.3 \pm 0.7$ & $>0.99$ & $30.12 \pm 1 \%$ & $>0.99$ & $7.4 \pm 0.1$ & $>0.99$ \\
\hline $1 \mu \mathrm{M}$ Pregabalin & $17.76 \pm 6 \%$ & 0.78 & $6.2 \pm 0.7$ & $>0.99$ & $30.9 \pm 1 \%$ & 0.17 & $7.3 \pm 0.1$ & $>0.99$ \\
\hline $100 \mu \mathrm{M}$ Gabapentin & $13.93 \pm 5 \%$ & 0.13 & $6.5 \pm 0.7$ & 0.36 & $28.19 \pm 2 \%$ & $>0.99$ & $7.2 \pm 0.1$ & $>0.99$ \\
\hline $1 \mu \mathrm{M}$ Gabapentin & $12.36 \pm 3 \%$ & 0.99 & $6.8 \pm 0.4$ & $>0.99$ & $27.72 \pm 2 \%$ & $>0.99$ & $7.3 \pm 0.1$ & $>0.99$ \\
\hline
\end{tabular}

1 


\section{Figure 1}

The effects of pregabalin or gabapentin in morphine induced GIRK channel activation.

Traces showing changes in fluorescent signal for various concentrations of morphine following application of $100 \mu \mathrm{M}$ pregabalin in (a) HEK 293- $\mu$ cells and (b) AtT20- $\mu$ cells. Drugs are added on the time as pointed by arrow and values are normalized to baseline reading. Concentration response-curves of morphine induced hyperpolarization of HEK 293- $\mu$ cells

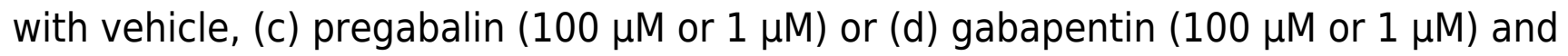
morphine-induced hyperpolarization of AtT20- $\mu$ cells with vehicle, (e) pregabalin (100 $\mu \mathrm{M}$ or 1 $\mu M)$ or (f) gabapentin (100 $\mu \mathrm{M}$ or $1 \mu \mathrm{M})(\mathrm{SEM}, \mathrm{n} \geq 5)$. 
HEK GIRK4 human $\mu$ receptor

a.

Fluorescence

(\% Predrug)

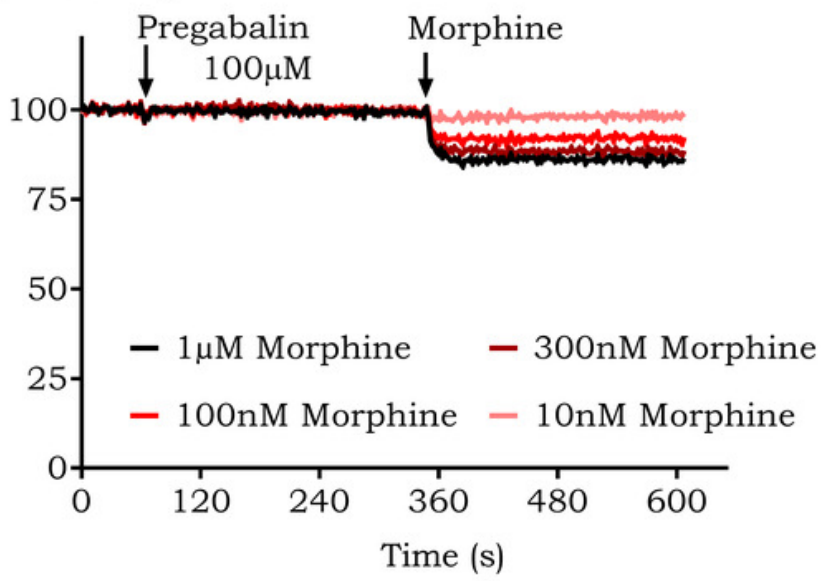

c.

$\Delta$ Fluorescence $(\%)$

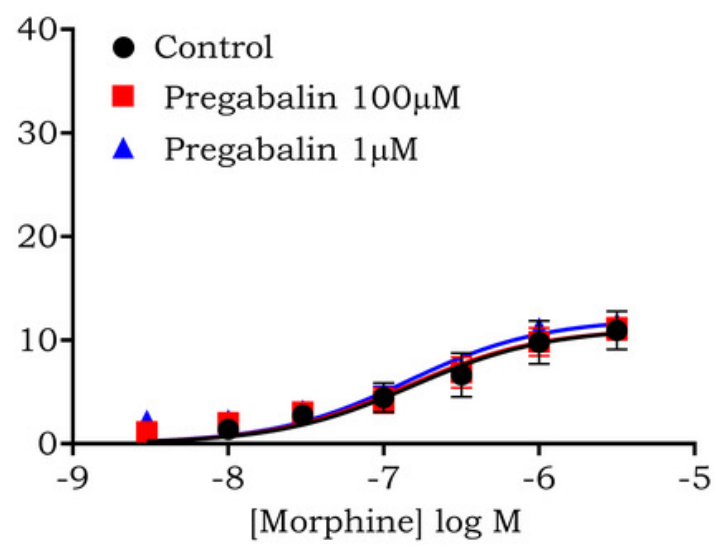

e.

$\Delta$ Fluorescence $(\%)$

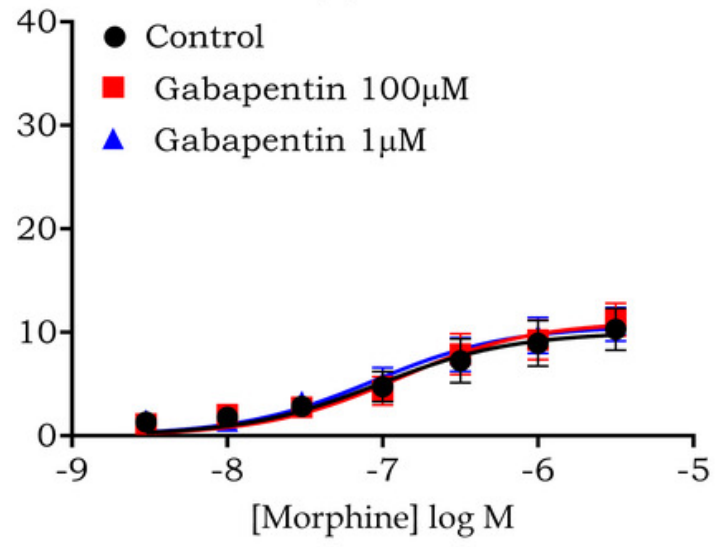

\section{AtT20 human $\mu$ receptor}

b.

Fluorescence

(\% Predrug)

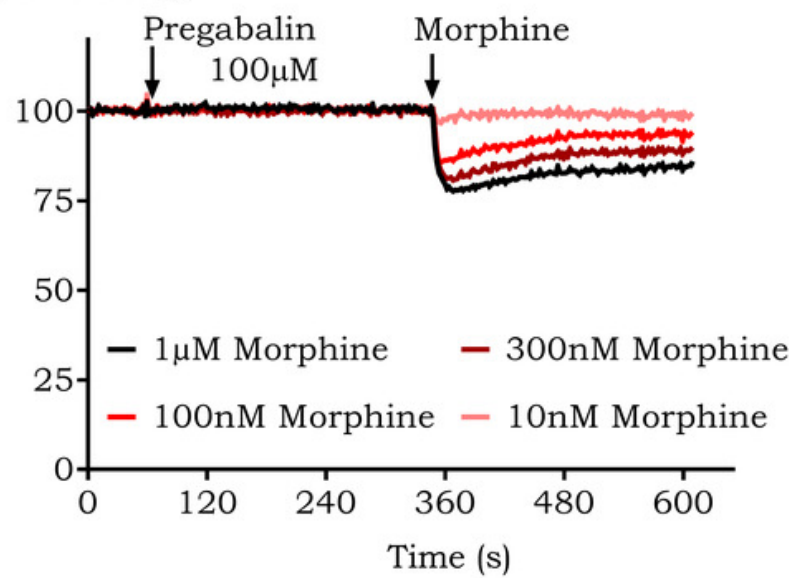

d.

$\Delta$ Fluorescence $(\%)$

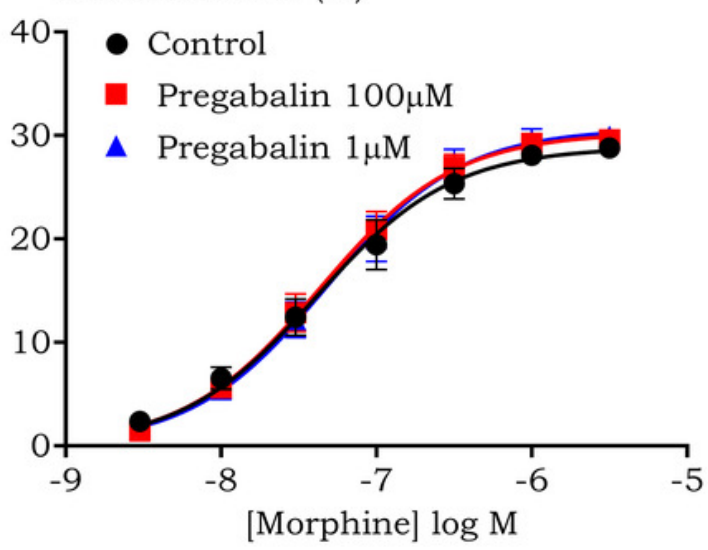

f.

$\Delta$ Fluorescence $(\%)$

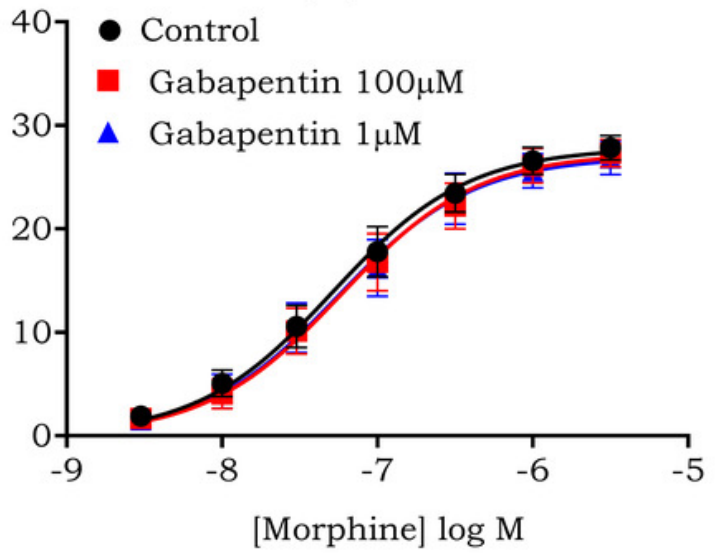




\section{Figure 2}

Morphine induced signal desensitization is not modulated by the presence of pregabalin or gabapentin in HEK 293 and AtT20 cells expressing human $\mu$ receptors.

Raw traces showing desensitization of fluorescence signals in (a) HEK 293- $\mu$ cells and (b) AtT20- $\mu$ cells on prolonged treatment with $10 \mu \mathrm{M}$ morphine after pre-incubation with vehicle (HBSS) or $100 \mu \mathrm{M}$ pregabalin. Scattered dot plots showing area under the curve after prolonged stimulation by morphine after exposure to pregabalin or gabapentin or vehicle in (c) HEK 293- $\mu$ cells and (d) AtT20- $\mu$ cells (SEM, $n \geq 5$ ). There was no difference in the maximum effect or potency of morphine-induced desensitization in HEK or AtT20 $\mu$ cells. 


\section{HEK 293 GIRK4 human $\mu$ receptor}

a.

Fluorescence (\% Predrug)

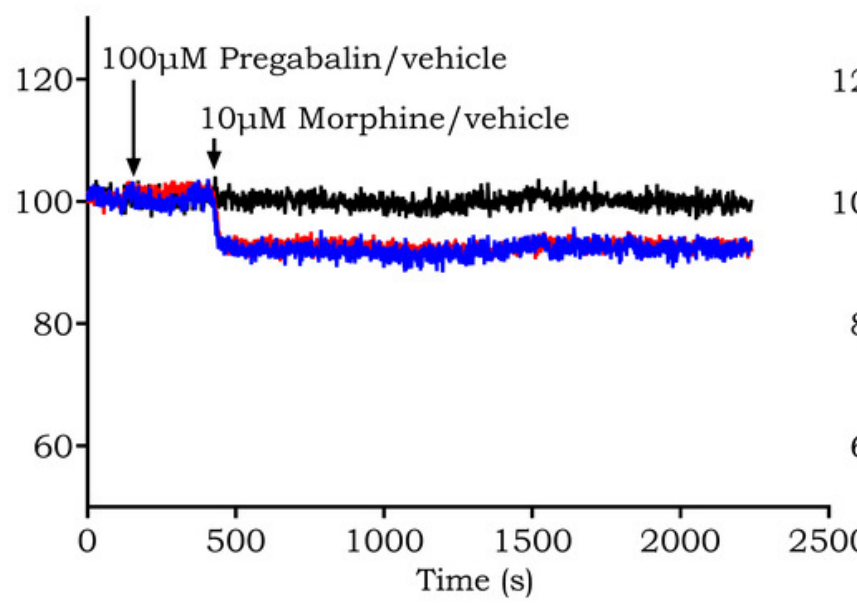

$-100 \mu \mathrm{M}$ Pregabalin + vehicle

- Vehicle $+10 \mu \mathrm{M}$ Morphine

$-100 \mu \mathrm{M}$ Pregabalin $+10 \mu \mathrm{M}$ Morphine

c.

AUC (Morphine response over 30 minutes)

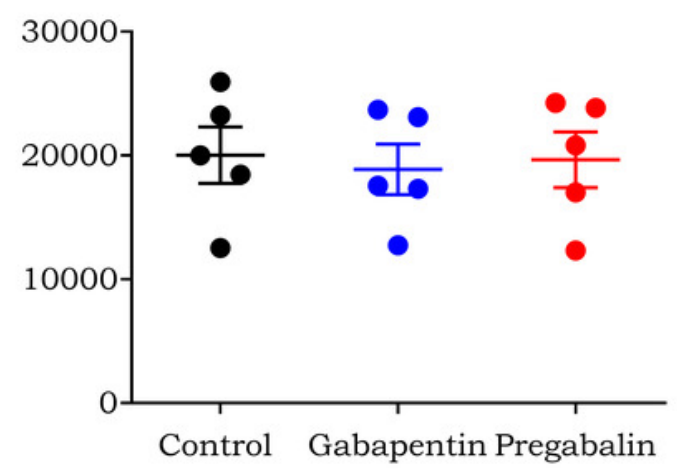

AtT20 human $\mu$ receptor

b.

Fluorescence (\% Predrug)

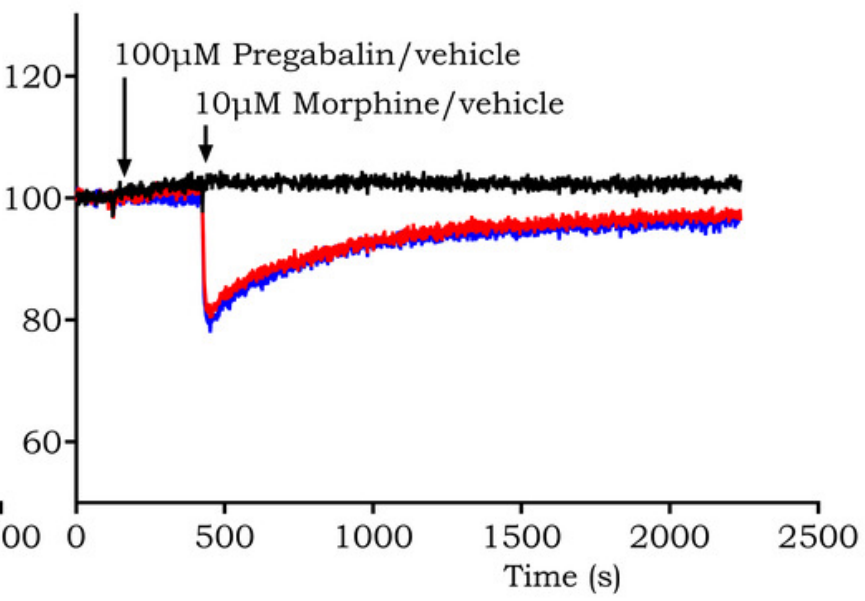

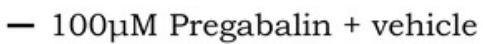

- Vehicle $+10 \mu \mathrm{M}$ Morphine

$-100 \mu \mathrm{M}$ Pregabalin $+10 \mu \mathrm{M}$ Morphine

d.

AUC (Morphine response over 30 minutes)

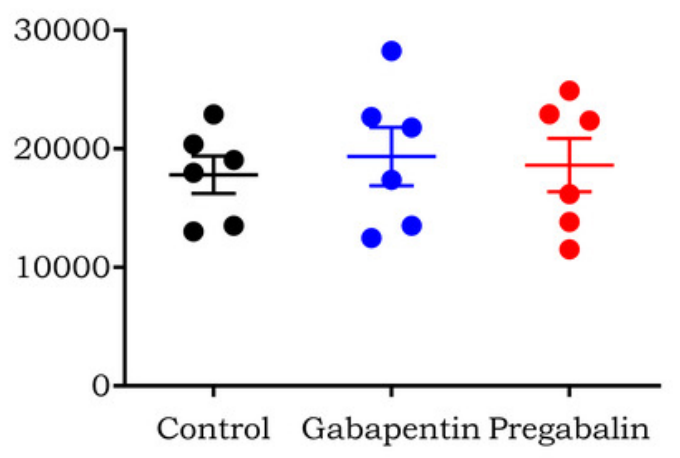


Figure 3

Concentration-response curve of morphine induced hyperpolarization in HEK $293-\mu$ cells after prolonged (60 minutes) pre-treatment with pregabalin or gabapentin.

Prolonged pre-incubation did not affect hyperpolarization induced by morphine. Data are expressed as percentage of change in fluorescence from baseline after correction for vehicle (SEM, $n \geq 5$ ).

$\Delta$ Fluorescence (\%)

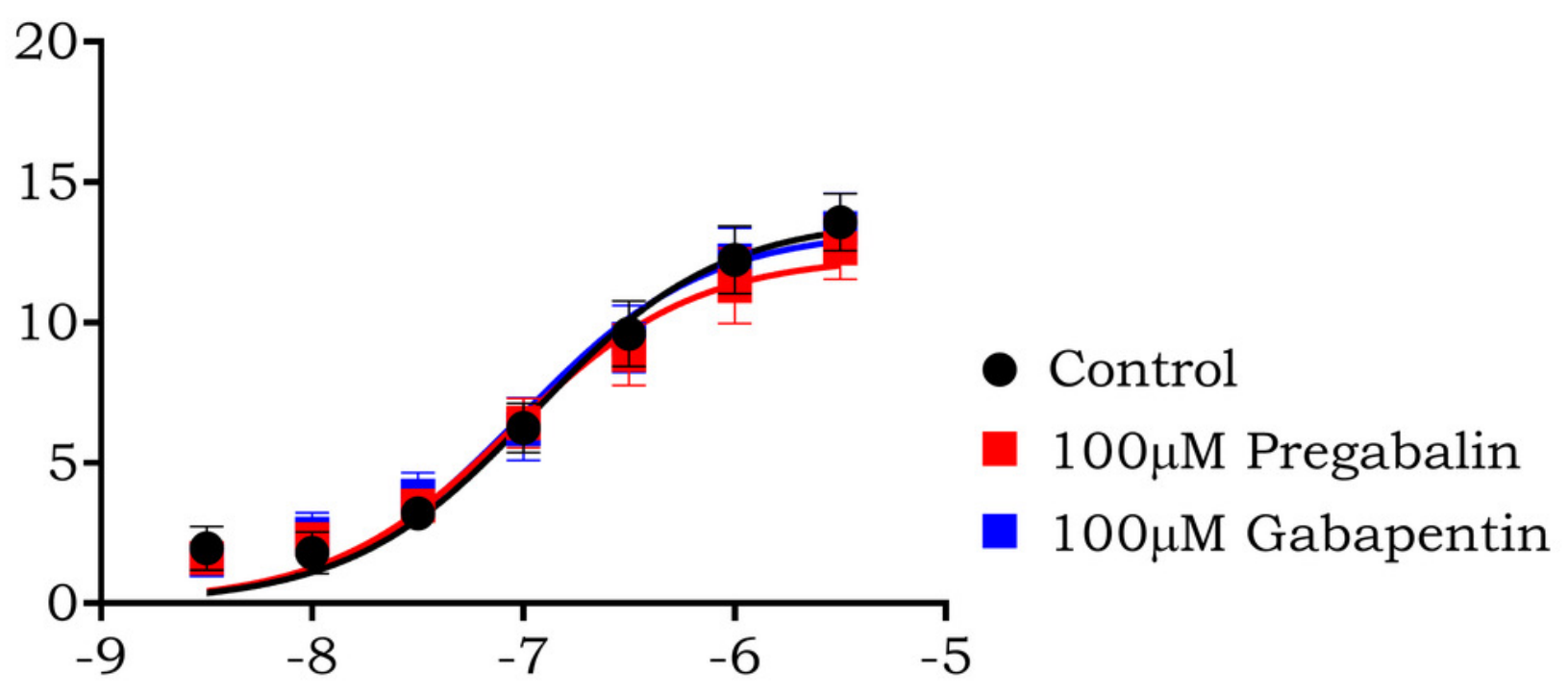

[Morphine] log M 


\section{Figure 4}

The effect of pregabalin or gabapentin on morphine induced cAMP production in HEK 293 GIRK4 cells expressing human $\mu$ receptor.

Concentration-response curves of morphine's response to forskolin-stimulated CAMP production in the presence of (a) $1 \mu \mathrm{M}$ gabapentin, (b) $100 \mu \mathrm{M}$ gabapentin or (c) $1 \mu \mathrm{M}$ pregabalin. Representative traces showing the effect of $100 \mu \mathrm{M}$ pregabalin on forskolinstimulated increase in cAMP levels in HEK- $\mu$ cells(d). An increase in BRET ratio $(461 / 542 \mathrm{~nm})$ corresponds to increase in cAMP production. (e) $100 \mu \mathrm{M}$ pregabalin increased the potency to inhibit forskolin-stimulated increase in CAMP, however, it did not change the response of (f) isoproterenol stimulated CAMP accumulation. 
a.

\% Inhibition of forskolin response

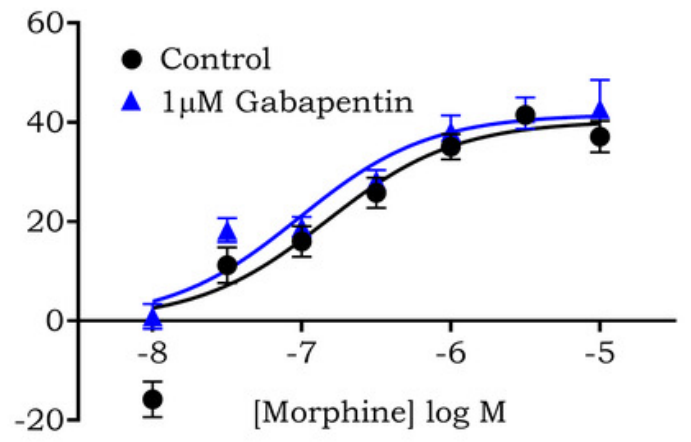

c.

$\%$ Inhibition of forskolin response

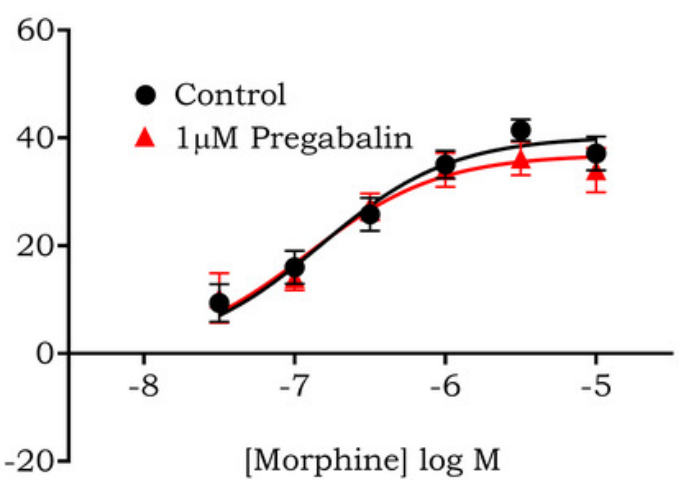

e.

$\triangle$ AUC- Inverse BRET ratio

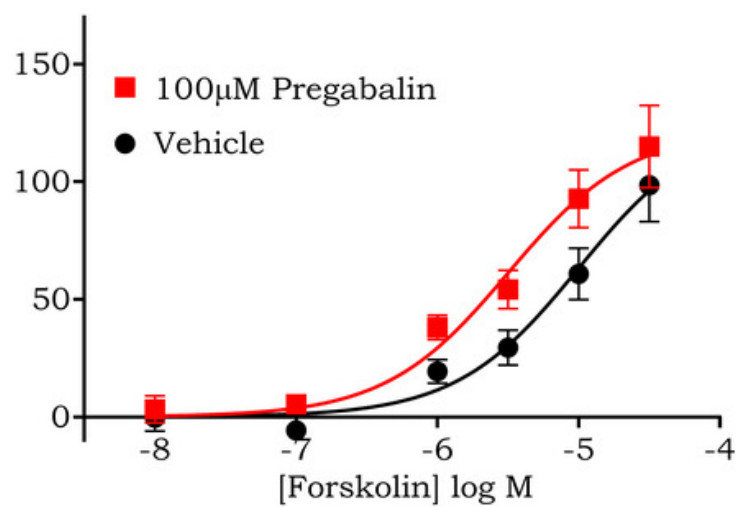

b.

$\%$ Inhibition of forskolin response

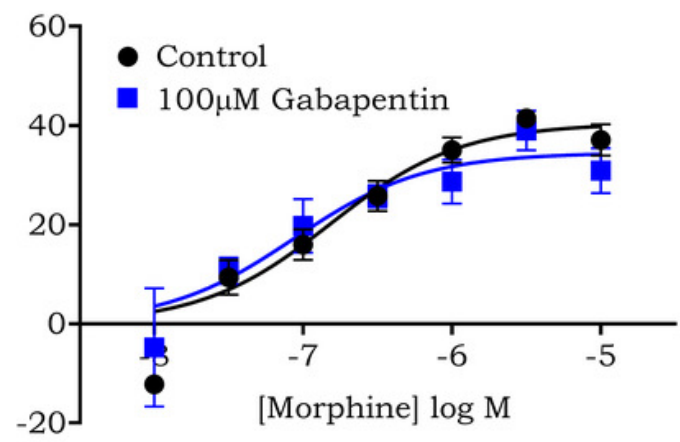

d.

Inverse BRET ratio $(461 / 532)$

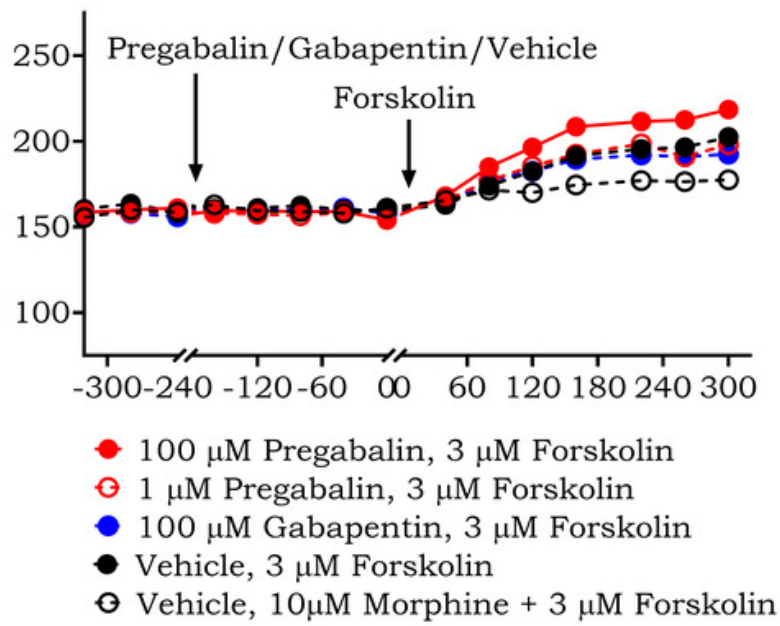

f.

$\triangle$ AUC- Inverse BRET ratio

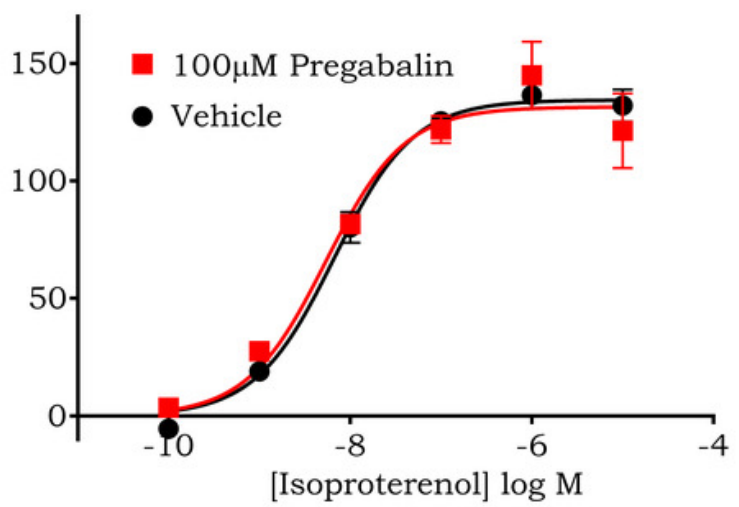




\section{Figure 5}

Pregabalin or gabapentin does not modulate morphine induced ERK phosphorylation in HEK 293 cells expressing human $\mu$ receptor.

Levels of ERK phosphorylation was assessed using ELISA assay as described in methods.

Data are calculated as percentage change from 100 nM PMA (positive control). Morphine stimulated ERK1/2 phosphorylation to a similar degree in the presence or absence of (a) $1 \mu \mathrm{M}$ or $100 \mu \mathrm{M}$ pregabalin or (b) $1 \mu \mathrm{M}$ or $100 \mu \mathrm{M}$ gabapentin (SEM, $\mathrm{n} \geq 6$ performed in triplicate).

a.

\% PMA

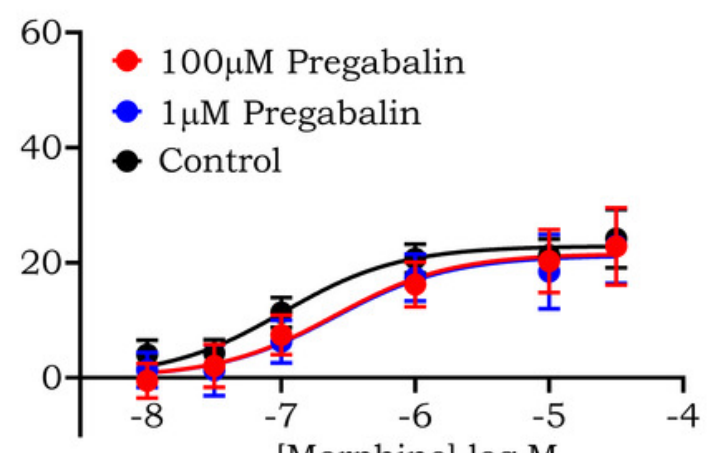

[Morphine] $\log \mathrm{M}$ b.

$\%$ PMA

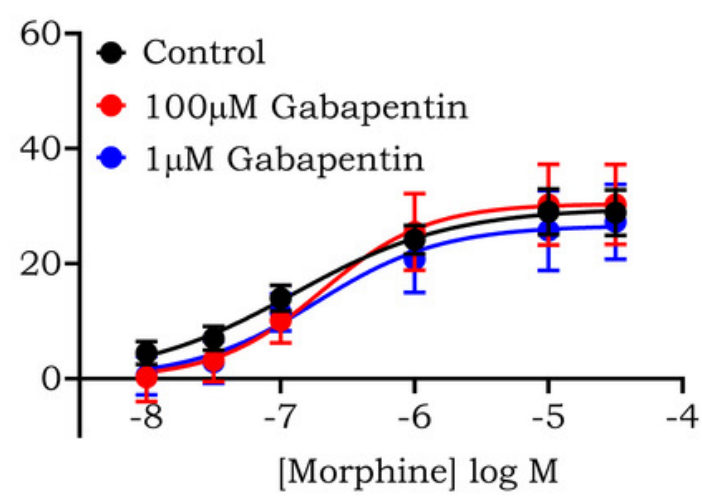

